\title{
The Impact of a Senior High School Tuition Relief Program on Poor Junior High School Students in Rural China
}

\author{
Xinxin Chen \\ Zhejiang Gongshang University, Hangzhou, China \\ Yaojiang Shi \\ Northwest Socioeconomic Development Research Center, Northwest University, Xi'an, China \\ Hongmei Yi, Linxiu Zhang \\ Center for Chinese Agricultural Policy, Institute of Geographical Sciences and Natural Resources \\ Research, Chinese Academy of Sciences, Beijing, China \\ Di Mo \\ LICOS (Centre for Institutions and Economic Performance), Katholic University of Leuven \\ James Chu and Scott Rozelle \\ Freeman Spogli Institute for International Studies, Stanford University, Stanford, CA, USA
}

\section{Acknowledgements:}

The authors would like to acknowledge the support of LICOS, K.U. Leuven, the grant from Poverty and Economic Policy Research Network (PEP) and the grant from the National Natural Science Foundation of China (70803047). We also thank Jade Chien, a supporter/advisor of the Rural Education Action Project, and her family. The project could not have been done without the collaboration of the Ningshan County, Shiquan County and Hanying County bureaus of education. We thank Jiang Jun, the former head of Education Bureau of Ningshan, for support during the project. The students from Northwest University of Xi' an, especially Fan Li and Huan Wang, carried out the survey work. We thank each and every one of them. 


\title{
The Impact of a Senior High School Tuition Relief Program on Poor Junior High School Students in Rural China
}

\begin{abstract}
A significant gap remains between rural and urban students in the rate of admission to senior high school. One reason for this gap may be the high levels of tuition and fees for senior high school. By reducing student expectations of attending high school, high tuition and fees can reduce student academic performance in junior high school. In this paper we evaluate the impact of a senior high tuition relief program on the test scores of poor, rural seventh grade students in China. We surveyed three counties in Shaanxi Province and exploit the fact that, while the counties are adjacent to one another and share similar characteristics, only one of the three implemented a tuition relief program. Using several alternative estimation strategies, including Difference-in-Differences (DD), Difference-in-Difference-in-Differences (DDD), Propensity Score Matching (Matching) and Difference-in-Differences Matching (DD Matching), we find that the tuition program has a statistically significant and positive impact on the math scores of seventh grade students. More importantly, this program is shown to have a statistically significant and positive effect on the poorest students in the treatment group compared to their wealthier peers.
\end{abstract}

JEL: I22; O12; O15

Keywords: Tuition Relief Program; Education Program Evaluation; Rural China 


\section{The Impact of a Senior High School Tuition Relief Program on Poor Junior High School Students in Rural China}

Students in most poor rural counties in China enroll in senior high school at a far lower rate than urban students (Yang, 2006). Nearly 90 percent of students in large cities in China attend senior high school. By contrast, only roughly 1 in 4 students attend senior high school in poor rural areas (Liu et al., 2009).

This gap in school participation may challenge the education system in meeting its goals and, in the longer run, harm the economy. In 2010 the Ministry of Education set a goal of having all students achieve 12 years of schooling (including primary, junior high and senior high education) by 2020 (Ministry of Education, 2010). While progress has been made in parts of the country, high rates of dropping out from junior high school (Mo et al., 2011) and low rates of matriculation to senior high school in poor rural areas (Yi et al., 2012) mean that educators are facing challenges if they are to meet its senior high school matriculation goals.

Lack of interest by poor rural students in attending senior high school also has implications for China's equitable development in the long run. When poor rural children end up working in factories or in construction sites to obtain short-run returns rather than studying math, language, English and computers, there is serious concern that the children are not learning the skills that will be needed to be gainfully employed in China's labor market in future (Rozelle et al., 2012). If China's economy continues to grow for the coming decade or more, the wage (which has been rising fast over the past several years-Cai, 2007) will almost certainly continue to increase. However, employers will only be willing/able to hire workers who have the sets of skills that are worth high hourly rates. Workers that lack such skills will either be forced to find employment in the informal economy (in which returns are low and expectations of future rises 
of income are negligible) or become unemployed (or drop out of society and possibly drop into organized crime). Hence, as rich urban students reap high returns, poor rural families might be left behind and China might face high rates of chronic unemployment, embedded inequality and, even possibly, growth-reducing instability.

There are many possible reasons for low matriculation rates to senior high school among poor rural students. First, low matriculation to senior high school may be due to the fact that China's education system is highly competitive and students in poor, rural areas are not able to compete (Wang et al., 2011). Second, it may be that students do not understand the importance of getting more schooling; that is, they may lack information about the importance of continuing in their education (Loyalka et al., 2010). Third, it might be that students want to go, but, the current rates of tuition and fees for senior high school—which are among the highest rates in the world for rural public senior high schools — is unaffordable (Liu et al., 2009).

Our senior high tuition relief program is designed to improve our understanding on the third reason (high tuition) for the low matriculation rates of poor rural students and to counteract the negative effects of high tuition. In China senior high school is non-compulsory and tuition (at least until recently) must be almost fully paid out-of-pocket. When tuition is expensive, poor families and students may make a decision not to go to senior high school (Liu et al., 2009). Indeed, the cost of sending a student to senior high school is many times more than a poor rural family's per capita annual income. In poor rural areas in Shaanxi Province, the annual income per capita was only 2,400 yuan in 2008 (Ankang Statistics Bureau, 2009). However, senior high school tuition and fees cost an average 8,000 yuan per year-more than 3 times the annual income of a poor family. Moreover, the opportunity cost of going to senior high school has increased. That is, a student attending high school cannot work or otherwise earn an income for 
his or her family. With the earnings of a typical unskilled worker reaching over 11,000 yuan per year (Huang et al., 2011), opportunity costs more than double the direct (cash) costs of going to senior high school. Waiving tuition thus has high potential in increasing enrollment rates. Indeed, since tuition was waived for primary and junior high students, the enrollment rate of junior high students in rural China has increased significantly (Ministry of Education, 2009).

High tuition also may reduce enrollment in senior high school among poor rural students in a second important way. Students, their parents and teachers may reduce their expectations for high school attendance if tuition seems prohibitive. These reduced expectations of senior high school attendance might depress student academic performance starting as early as seventh grade (as they enter the level of schooling immediately proceeding senior high school). Because academic performance remains a primary prerequisite to enrollment in senior high school (Brown and Park, 2002; Knight and Song, 2000; Connelly and Zheng, 2002), poor students' chances of attending senior high school might be negatively impacted by high tuition even before they enter ninth grade (the final grade of junior high school).

The overall goal of this paper is to evaluate the effectiveness of a senior high school tuition relief program in promoting education in poor rural areas and encouraging students to exert more effort in preparing for senior high school. More precisely, we are interested in knowing whether students will respond to the tuition reduction program by (working harder and) performing better if a school district offers tuition relief and informs students in junior high school of this fact.

To accomplish this goal, we draw on the fact that one poor county in southern Shaanxi Province - the County of Ningshan — implemented a senior high tuition relief program. In contrast, two neighboring (and quite similar) counties — Shiquan and Hanyin — did not implement 
any tuition relief programs. Hence, we believe that this arrangement can serve as a natural experiment, allowing us to evaluate the impact of Ningshan's senior high tuition relief program on the academic achievement of poor rural seventh grade students. To analyze our data and address concerns that we might not have a perfect experiment (that is, although similar, there may be other differences between Ningshan and Shiquan/Hanying besides the tuition relief program), we conduct Difference-in-Differences (DD) estimation, Difference-in-Difference-inDifferences (DDD) estimation, Propensity Score Matching (Matching), and DifferenceDifferences Matching (DD Matching). Above all, we are interested in examining whether the impact differs for the poorest students and the richest students. In other words, we also investigate whether the poorest students, who are from families that are more likely to be liquidity constrained, are affected by this program more than their richer peers.

In seeking to achieve such an ambitious goal, we also acknowledge certain limits. By the time of the endline survey in September 2010, the first cohort of students that would enjoy the benefits of the Ningshan tuition relief program, which officially started in September 2009, had only completed their first year of junior high school. Because of this, we are unable to quantify the impact of the program on how many students actually matriculated to high school due to the program. Indeed, we are restricted to being able to evaluate the effect of the tuition relief program on the effort of first year junior high school students, or more precisely, on their performance on two standardized math tests developed and executed by the research team (one conducted before the start of the tuition relief program in September 2009 and the other conducted after one year of the program in September 2010). We are also aware that our natural experiment covers only three counties in poor areas of rural China. There are hundreds of counties in other parts of China's poor rural areas. We believe that our work can inform the 
debate of whether tuition relief should be offered or not in these counties. However, we do not claim full external validity for other poor areas.

The rest of the paper is organized as follows. The first section introduces the tuition relief program, followed by our data collection and sampling methodology. We then turn to describe our analytic approach. Finally, we present the results of the study and discuss their implications.

\section{Ningshan County's Tuition Relief Program}

A tuition relief program implemented in the County of Ningshan provided us with an opportunity to examine the effect of such programs on the academic performance of junior high students in China's poor rural areas. Ningshan is a nationally designated poor county where rural per capita income was 3201 yuan (US\$ 500) in 2009.

Like other rural areas, the annual costs of attending senior high school far exceed the income of poor families. According to an official website administered by the Ankang Prefecture Bureau of Education, tuition for senior high schools in 2010 was 1500 yuan per year. ${ }^{1}$ There were also fees and other miscellaneous expenses. In interviews with Ningshan, Shiquan and Hanying officials, we were told that about 80 percent of students lived in the dormitories on campus in their senior high schools. According to a survey of senior high school students elsewhere in Shaanxi Province, on average, a typical senior high student had to pay additional 8000 yuan per year for accommodation, food, and learning materials (Liu et al., 2010).

The Ningshan tuition relief program was announced at the end of July in 2009 during summer vacation. The local government promised to pay annual tuition (1500 yuan) for three years in senior high school for students who were among the top 500 students in the entrance

\footnotetext{
${ }^{1}$ All the study counties in this paper, i.e. the county of Ningshan, Shiquan and Hanyin are located in the same prefecture of Ankang in Shaanxi Province.
} 
examination to the senior high school. As the average annual enrollment in the only senior high school in this county was about 550, program coverage was 91 percent. In effect, the program meant that most students enrolling after August 2009 did not need to pay tuition.

Moreover, all junior high students were informed of the tuition relief program. Although in September 2009 only $15 \%$ of junior high students knew about the program, when we revisited the schools in March 2010, 100 percent of students that we randomly selected from grade 7 (or the first year of junior high school) were aware of the program and could generally describe the nature of the program. According to interviews with officials in the bureau of education, the government conducted an intensive promotional effort to make this program known to all junior high students in early October 2009. Hence, if there were any effect of the program, it is possible that it could have appeared as early as grade 7.

The neighboring counties of Shiquan and Hanyin are located in the same prefecture as Ningshan. In China, students in the same prefecture usually are required to take the same courses, use the same textbooks, take the same entrance examination to senior high school and pay the same amount of tuition. This is true in the case of Ankang Prefecture.

There were other similarities between Ningshan and Shiquan/Hanying counties. Like Ningshan, Shiquan and Hanying counties are nationally- or provincially-designated poor counties. $^{2}$ In 2009, the rural per capita income was 3323 yuan (\$519) in Hanyin and 3338 yuan (\$522) in Shiquan. All three counties are extremely mountainous. Per capita fiscal revenues are nearly zero in all three counties, meaning that almost all educational expenditures are financed by transfers from governmental units in the prefecture, province and national levels. Moreover,

\footnotetext{
${ }^{2}$ In 1994, China's government launched a poverty-reduction initiative under the "8-7 Plan" and designated 592 counties as national designated poor counties. Provinces followed with their own initiatives. In our sample, Ningshan and Hanyin counties are nationally designated poor counties, and Shiquan is a provincially designated poor county.
} 
more than 98 percent of the rural populations in all three counties are Han. In sum, in terms of characteristics like poverty rates, geography, fiscal capabilities and ethnic make up, the three counties are almost identical.

The sample students also appear to be similar in nature to what would be expected in a poor, rural setting in China. For example, we find $6 \%$ more boys than girls, a ratio similar to that cited in the Ministry of Education's 2010 Annual Yearbook: 7\% more boys than girls. Approximately $98 \%$ of the seventh graders in our sample are aged between 11 and 15 years.

Although the main sample at the time of the baseline survey (September 2009) included a total of 36 schools and 3121 students, there was some attrition by the time of the endline survey in September 2010 (Figure 1). For various reasons (dropouts, absences, death, etc.), by the time of the endline survey we were only able to follow up with 2742 students - 672 students in Ningshan County (the treatment group) and 2070 students in Shiquan and Hanyin counties (the control group). In spite of attrition of 379 students, the attrition rate is almost the same (12\%) in both groups, thus reducing the probability of attrition bias, ${ }^{3}$

Table 1 shows that study students were balanced in the key dependent variable (raw math test score in 2009-row 1). To be specific, the mean math score in the County of Ningshan (the treatment group) was 54.82 and the mean math score in the Counties of Shiquan and Hanyin was 54.29. There was no statistically significant difference between them. In addition, rows 2 to 13 show that there were no statistically significant differences at the level of most control variables: the preschool history of the student, the sibling dummy for the student and the occupation dummy for the parent.

\footnotetext{
${ }^{3}$ The attrition rate, while high, is not unusual. In a working paper based on data from a county in Shanxi province (Di et al., 2011), the drop out rate of poor rural students between the first month of the first year of junior high (grade 7) and first month of the second year of junior high (grade 8) is reported to be 13.3 percent.
} 
However, there was one fundamental difference between Ningshan and Shiquan/Hanying. There was no tuition relief program in either Shiquan or Hanying. Because of this, we believe we have a natural experiment, designating students in Ningshan as treatment students and students in Hanyin and Shiquan as control students. That is, unlike the 7th graders in Ningshan County that knew about the tuition relief program in senior high school, students in the control group who are in their first year of junior high school were well aware of the fact that if they wanted to go to high school they (or their parents) would have to pay tuition.

\section{Sampling and Data Collection}

To evaluate the effectiveness of the tuition relief program, we collected data in Ningshan County and two control counties, Shiquan and Hanyin. All 36 junior high schools in the three study counties were surveyed. In addition, in Ningshan County, all seventh grade classes in all six junior high schools were selected. In Shiquan and Hanyin counties, a subset of seventh grade classes in each of the 30 junior high schools was randomly selected because Shiquan and Hanyin had a larger population (and it would have been too costly to survey all students in all classes).

In every sample class, we surveyed all the students. In total, our survey covered 3121 seventh graders. These students were in 69 classes and spread over 36 junior high schools.

Two surveys were conducted. Our baseline survey occurred in early September 2009 at the beginning of the autumn semester, and our evaluation survey occurred almost precisely one year later in September 2010. During each round of survey, the enumeration team visited each school and conducted a two-block survey.

The first block of the survey was a 30 minute standardized math test. This test was given to all sample students in the treatment group and the control group. Because we designed, printed 
and administered the survey/test ourselves, we know that there was no coaching for the test before our survey. Since the test was administered at the start of the school year, we also know that neither students nor teachers shifted their efforts from other subjects to math. In addition, even if the students knew about the program, rural students seldom take extra tutoring classes during summer vacation. As such, the math test scores we collected in early September can reasonably be used as the pre-program outcome. When we gave the standardized tests, the connection to the treatment (the tuition relief program) was kept blind in both the treatment and control schools. In order to do so, none of the enumerators were informed about the goal of the survey except for a core staff of the two lead enumeration team managers.

In our analysis, we report raw math test scores (full score equal to 100) without any further manipulation for the ease of interpretation. As a robustness check, we also used the normalized z-score of math score. The normalized score was created by subtracting the average test score of all sample students from the raw score for each student and then dividing it by the standard deviation of the test scores of all sample students in the same grade. With this transformation, the normalized test score is interpreted as the units of standard deviations from the mean score of all students in the same grade. When we replicate our empirical analyses using normalized scores, the results are almost the same. Using normalized scores has the one advantage of facilitating comparison with other educational programs.

In the second block enumerators collected data on the demographic and socioeconomic characteristics of students and their families. From this part of the survey we are able to create our control variables. The dataset includes measures of each student's age (measured in years), gender (described by an indicator gender, which is equal to one for boys, and zero for girls), sibling information (described by an indicator, no sibling which is equal to one for student had 
no siblings, and zero for students who had siblings), and student pre-schooling and kindergarten information (described by the indicator of preschool and kindergarten, which equals to one if students attended either preschool or kindergarten), father and mother's age (measured in years), father and mother's education level (completed at least middle school) and father and mother's occupation (described by an indicator variable called occupation, which equals one if a student's parent works in agriculture, and zero for the parent who works in the non-agricultural sector).

As part of the second block students were also asked to indicate which assets their family owned from a list of 30 household asset items. Using these data, we generated an asset index using principal component analysis to measure the wealth of each household. Following the method by Filmer and Pritchett (1998), we used scoring factors from the first principal component to create the asset index. It is in fact a weighted average of the observed 30 variables of assets, and variables with higher coefficients have more weight in determining the score. The higher the asset index is, the wealthier the household is. Based on this asset index, we divided the students into five equal-sized groups and created the variables of Poorest, Second, Median, Fourth and Richest to represent the students whose household wealth was among the bottom 0$20 \%$, top $60-80 \%$, top $40-60 \%$, top $20-40 \%$ and top $20 \%$ and above.

\section{Analytical Approach}

In this section we introduce our analytical approach. In the analysis we use a number of alternative estimation procedures to examine the impact of the tuition relief program. In particular, we use DD, DDD, Matching and DD Matching.

\section{Basic Estimation Methodology}


We are interested in understanding the mean impact of "treatment on the treated" or TT, which is the average impact of the program among those treated (Smith and Todd, 2005):

$$
T T=E\left(\left(Y_{1}-Y_{0}\right) \mid X, D=1\right)=E\left(Y_{1} \mid X, D=1\right)-E\left(Y_{0} \mid X, D=1\right)
$$

where we denote $Y_{1}$ as the outcome (student test scores) after the treatment, $Y_{0}$ as the outcome before the treatment; and $\mathrm{D}=1$ stands for the group of students who participated in the program in 2009, $D=0$ stands for those who did not participate in the program in 2009; and $\mathrm{X}$ is a vector of control variables. In reality, we do not observe the counterfactual mean, $E\left(Y_{0} \mid X, D=1\right)$, or the mean outcome for the students who participated in the program had they not participated in 2009.

To create this counterfactual mean, we employ a difference-in-difference method (DD). Let $t$ and $t$ ' denote the time after the intervention (2010) and time before the intervention (2009). The standard DD estimate is given by:

$$
D D=\left[E\left(Y_{t} \mid D=1\right)-E\left(Y_{t^{\prime}} \mid D=1\right)\right]-\left[E\left(Y_{t} \mid D=0\right)-E\left(Y_{t^{\prime}} \mid D=0\right)\right]
$$

In estimating equation (2), we are able to compare the outcomes before and after the intervention status change for students affected by the program $(\mathrm{D}=1)$ to students not affected by the program $(D=0)$. We assume that the average improvement in test scores between September 2009 to September 2010 among students in Ningshan would have been the same as the improvement among students in Hanyin and Shiquan (the "parallel trend" assumption). If so, by subtracting the average gain of test score in Ningshan from the average gains in Hanyin and Shiquan, common trends are differenced out and we are left with an estimate of the treatment on the treated (Smith 2004).

In addition to the standard DD estimator, we implement three other DD estimators: an "unrestricted" version that includes $Y_{t^{\prime}}$ as a right hand variable, an "adjusted" version that includes other covariates in addition to the treatment variable (in our case they are a series of 
control variables from 2009 or the pre-program period), and an unrestricted/adjusted model that combines the features of both the "unrestricted" and "adjusted" model. The unrestricted and adjusted DD estimators relax the implicit restrictions in the standard DD estimator that the coefficient associated with $Y_{t}$, (pre-program outcome) and covariates in $t^{\prime}$ (pre-program period) equals one. The combination of unrestricted and adjusted DD estimators relaxes both of these assumptions. In summary, the models to be estimated are:

Model (1), Restricted \& Unadjusted: $\Delta$ Score $_{i}=\alpha+$ SProgram $_{i}+\varepsilon_{i}$

Model (2), Restricted \& Adjusted: $\Delta$ Score $_{i}=\alpha+$ SProgram $_{i}+\beta X_{i}+\varepsilon_{i}$,

Model (3), Unrestricted \& Unadjusted: $\Delta$ Score $_{i}=\alpha+\delta$ Program $_{i}+\gamma$ Score_OO $_{i}+\varepsilon_{i}$

Model (4), Unrestricted \& Adjusted: $\Delta$ Score $_{i}=\alpha+\delta$ Program $_{i}+\gamma$ Score_09 $_{i}+\beta X_{i}+\varepsilon_{i}$ where, $i$ is an index for the student, $\Delta$ Score $_{i}$ is the change of the score of student $\mathrm{i}$ between 2009 and 2010; Program $_{i}$ is the treatment variable (which makes $\delta$ the parameter of interest). In our analysis, $\operatorname{Program}_{i}=1$ if the student i participated in the program $\left(\right.$ Program $_{i}=0$ if the student $\mathrm{i}$ did not participate in the program). Finally, the term $\mathbf{X}_{i}$ is a vector of covariates that are included to capture the characteristics of student, his/her parent and household which includes the age, gender, preschool history, number of siblings of the student, the educational attainment, occupation, age of the student's father and mother, and wealth status of the household.

It is important to remember that the identification of the causal effect using DD relies on the assumption that absent the policy change (or intervention of the program in our case), the average change in $Y_{t}-Y_{t^{\prime}}$ would have been the same for the treated and the comparison groups. This "parallel trend" assumption can be formally expressed as:

$$
E\left(Y_{0, t} \mid D=1\right)-E\left(Y_{0, t^{\prime}} \mid D=1\right)=E\left(Y_{0, t} \mid D=0\right)-E\left(Y_{0, t^{\prime}} \mid D=0\right)
$$


As might be expected, the effectiveness of DD depends on the validity of this assumption. In this study, the difference in these differences can be interpreted as the causal effect of the tuition relief program under the assumption that in the absence of program, the differences in the test scores of students would not have been systematically different in the treatment and control groups. This identification strategy might be invalid if the pattern of differences in student scores varies systematically across counties.

To validate our estimates, we can further draw on the assumption that rich students were not financially constrained when making decisions to go to senior high school and therefore were not affected by the tuition relief program. We can thus use rich students as an additional control group to look at the effect of the tuition relief program on the test score of the poor student who might be affected by the tuition program. In this way we can define the Difference-inDifference-in-Differences (DDD) estimator. The model to be estimated is:

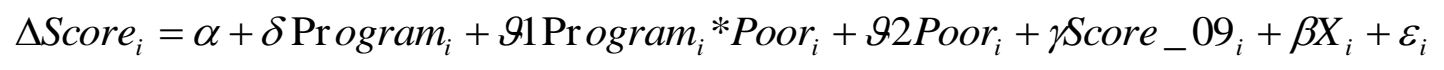

where Poor $_{i}$ is the wealth indicator dummy for student i. It equals 1 if the student's asset index is lower than the median and zero if the asset index is higher than the median. Here $\vartheta 1$ is the coefficient of our interest.

\section{Sensitivity Analysis}

In our paper we also use different methods to serve as robustness checks. To begin with the reality of our question (understanding the effect of the intervention on the student score) may mean that even though we control for a large number of observable variables in 2009 in the adjusted and unrestricted versions of the DD estimates, there are other unobservable factors that may be compromising the parallel trend assumption. 
Because of the potential existence of other differences between students who participated in and students who did not participate in the program, we also use the method of propensity score matching (PSM), an approach that does not require the parallel trend assumption. With a sufficient region of support (or common support), it is possible to estimate the propensity scores of all students and compare the outcomes of students who participated in and students who did not participate in the program that have similar propensity scores. $4 \mathrm{We}$ can obtain the mean impact of the treatment on the treated by the following equation (Dehejia and Wahba, 2002; Smith and Todd, 2005):

$$
E\left(Y_{1}-Y_{0} \mid D=1\right)=E\left(Y_{1} \mid D=1\right)-E_{Z \mid D=1}\left\{E\left(Y_{0} \mid p(Z), D=0\right)\right\}
$$

where $p(Z) \equiv \operatorname{Pr}(D=1 \mid Z)$ is the propensity score. Matching is based on the assumption that outcomes ( $Y_{0}$, which in our case is the score of the students) are independent of participation, conditional on a set of observable characteristics (Rosenbaum and Rubin, 1983). By matching students who participated in and students who did not participate in the program with similar values of $\operatorname{Pr}(D=1 \mid Z)$, any differences in $E\left(Y_{0}\right)$ between the two groups are assumed to be differenced out when calculating the above equation. The assumption of matching is:

$$
E\left(Y_{0} \mid Z, D=1\right)=E\left(Y_{0} \mid Z, D=0\right)
$$

The observable covariates $Z$ should include the characteristics that determine participation. In our analyses, $Z$ includes a number of variables including the characteristics of the student, his/her parent and household.

To implement PSM successfully, the common support of the propensity scores for participating and non-participating students should be fairly wide. Moreover, there should be

\footnotetext{
${ }^{4}$ We need to note, however, that a recent study found that the propensity score matching method is sensitive to the covariates used to estimate the scores and that combination of matching with DD was superior (Smith and Todd 2004).
} 
balance in the distributions of characteristics between treatment and control groups. Wide common support means that there must be a fairly large overlap in the propensity scores between the treatment and control groups. In our sample, we will try to examine whether the common support is fairly wide or not before using PSM.

PSM is a more general method than standard linear regression since it does not require assumptions about linearity or constant treatment effects, and thus improves bias correction. Moreover, imposing common support in PSM can lead to efficiency improvements, especially when the sample size is small. It should be noted, however, that PSM estimates are only unbiased if the unobservables are correlated with the observables upon which the matching is based.

Even though we control for the individual observable differences estimating the propensity score, there may still be systematic unobservable differences between the outcomes of students who participated and students who did not participate in the program. The systematic differences could arise, for example, because the student's decision to participate is based on some unmeasured characteristics. Such differences could violate the identification conditions required for matching (Smith and Todd, 2005).

To eliminate the bias due to time-invariant unobservable differences between students who participated in and students who did not participate in the program, we will extend the cross-sectional PSM approach to a longitudinal setting and implement a difference-in-differences matching (DDM) strategy. With DDM we can exploit the data on the students in the treatment in 2009 to construct the required counterfactual, instead of just using the data in 2010 (as is used in the PSM analysis). The advantage of DDM is that the assumptions that justify DDM estimation are weaker than the assumptions necessary for DD or the conventional PSM estimator. DDM 
removes time invariant unobservable differences between students who participated in and students who did not participate in the program conditional on $\mathrm{P}(\mathrm{Z})$, a clear advantage over cross-sectional PSM. ${ }^{5}$

In performing DDM we match by using the log odds-ratios and the same nearest neighbor matching methods with replacement used in our PSM approach (which were described above). In addition, we will also compute the "adjusted" version where the control units are weighted by the number of times that they are matched to a treated unit. The standard errors are bootstrapped using 1000 replications.

\section{Results}

\section{Effect of the Tuition Relief Program: Descriptive Statistics}

The descriptive statistics suggest that the Ningshan tuition relief program had a significant impact on students. As discussed above, the baseline test scores of the students in the treatment (54.82) and control group (54.29) were almost the same in 2009 (Table 2, row 1). If one had just looked at the rise of test scores of the control group (the endline score was 69.55, significantly higher than the baseline by 15.26 points - column 3, rows 2 and 3), one might be tempted to say that students were still learning better despite knowing that they would have to pay high levels of tuition in senior high school. However, when comparing the performance of the treatment and control students, it can be seen that the improvement in test scores of the control students was less than the progress made by the treatment students. The mean of the endline test scores of the treatment students was 73.19 (column 2, row 2). This was 18.37 points higher (and statistically significant) than the baseline (row 3). Most importantly, the rise in the

\footnotetext{
${ }^{5}$ Using outcomes from experimental data as a benchmark, Smith and Todd (2004) found that DDM performed better than DD or PSM methods.
} 
tests scores of the treatment students (18.37) was higher than the rise of the test scores of the control students (15.26-row 3). Moreover, the 3.11 point higher rise in the test scores of the treatment students is statistically different at the 1 percent level of significance (column 4). From these basic descriptive statistics, it appears as if the Ningshan Tuition Relief program succeeded in stimulating the interest/effort of the average student in Ningshan relative to the average students in Shiquan and Hanying.

Since poor students are more likely to be financially constrained (indeed the tuition relief program is primarily motivated by the benefit it will bring to the children of poor families), we are interested in knowing if students from poor families are likely to be most affected by the program. To test this proposition, we divided the sample of students in the study counties into five equal sized groups (from poorest to richest), based on a ranking by their asset index. When examining the descriptive statistics, we find that while the poor did benefit, it appears that all students, whether rich or poor, benefited from the tuition relief program. According to Table 3 , the test scores of all the students in each of the wealth status groupings rose between the baseline and endline surveys (column 7).

While Table 3 demonstrates that students in all Wealth Categories that enjoyed tuition relief (those in Ningshan County) benefited, the average point rise in some increased more than others. A little surprisingly, the richest students seemed to benefit most from the program. After the program, the difference in the rise of score between the two groups was 4.38 points (column 7, row 5). This does not mean that the poorest students did not benefit. In fact, ignoring the scores of the students in the richest categories, the poorest students saw their average scores rise the most (the difference in the rise between the treatment group and control group was 3.82 row 1). The puzzle arises in the nonlinearity from the poorest to the richest. The second poorest 
students seem to benefit least from the program since the difference in the rise between the treatment and control groups was only 1.17 points (column 7 , row 2). After this (as one moves from the second to the fifth group), scores generally rise (rows 3 to 5).

Why is it that we see that the richest students are responding most to the program? There are two possible explanations. First (potential explanation 1), in Table 3, we are looking only at descriptive statistics. As such, we are only comparing trends in single variables (that is, they are not conditioned on other factors). Hence, it could be that the rises in the scores of the richer students are due to factors that are enjoyed by the richer students, which are in turn correlated with the treatment (in this case enjoyed by richer students in Ningshan), but actually unrelated to the treatment. Second (potential explanation 2), it could be that the treatment is actually triggering a response among richer students that is leading to higher test scores. For example, it might be that the richest students, who heretofore have not had to compete with poorer students (since poorer students were effectively rationed out of going to senior high school by the high tuition rates) begin to realize that they are losing one of the advantages that they have had in the past in gaining entrance to high school. In response, it could be that they began to work harder. While we are never able to fully isolate the reason, in the next section we seek to control for the number of the observable characteristics of students (using the regression models spelled out from model (1) to model (4)). If we control for factors as many as possible that differ between poor and rich students (e.g., the educational levels of their parents, etc.), we may be able to validate or invalidate potential explanations. Unfortunately, since the motivation that drives the potential explanation is not observable, we will not ever be able to confirm exactly what is driving our findings. 
In sum, based on the descriptive statistics, the tuition relief program seems to increase the academic performance of students in the treatment schools. However, the effect of this program differs across different students in terms of wealth status, and while the poorest students do gain from the program, the richest students are, surprisingly, gaining most from the program.

\section{Effect of the Tuition Relief Program: Multivariate Results}

When analyzing the effect of the tuition relief program using a multivariate approach (based on equations 1 to 4 ), the results are largely consistent with the descriptive statistics in terms of the overall impact (Table 4, Table 5). According to our analysis (and consistent with the findings in Table 2), there is a positive and statistically significant impact of the tuition relief program on the test scores of students. In the estimation of equation 1 , the coefficient of the program treatment, 3.11 (row 1, column 1) is (as it should be) exactly the same as that in the descriptive statistics, 3.11 (Table 2, row 3, column 4). As we add covariates (as we specify in equations (2) to (4) to increase the efficiency of the estimation), the results demonstrate consistently the positive and significant effect of the tuition relief program (row 1, columns 2 to 4). The coefficients range from 2.85 to 3.40. In short, when we use a Difference in Difference approach, we find that the tuition relief program has had a positive and significant effect on improving the academic effort (as measured by the scores of the standardized tests) of the average student.

Importantly, the results of our findings of the multivariate analysis when we examine the effect of the tuition program on the poorest students in the sample (those with the lowest Asset Indices) differ from the descriptive findings. As seen in Table 5, when we control for all of the covariates and then add an interaction terms between the treatment variable (Tuition Relief Program dummy) and a dummy variable representing the poorest students, we find that the 
program's effect is primarily on the poor. This result may have been "disguised" when only examining the descriptive statistics. Specifically, while the average treatment effect (which in this case is the average treatment effect for all of the students except the poorest) is still positive (2.33), the standard error is relatively large. In other words, we cannot reject the hypothesis that the tuition relief program's effect on all but the students in the poorest asset category is zero. However, the positive (and large) coefficient on the Poorest * Program interaction variable (3.83) means that the test scores of the poorest junior high students are 3.83 points higher (and significantly so) than that of other students. Hence, if the multivariate results are to be taken seriously, the results as a whole (that is, both descriptive and multivariable one) demonstrate that the tuition relief program increased student academic performance in junior high. More importantly, the poorest students, or those who were most likely to be from families that were financially constrained, benefitted most from the program.

\section{Effect of the Tuition Relief Program: Matching Results}

As mentioned, a difference-in-difference methodology relies on assumptions of parallel trends. That is, we assume that students in Ningshan (the treatment county) would have improved at the same rate as students in Hanyin and Shiquan had there been no policy. However, some may argue that Ningshan County may be unique. For example, Ningshan students (and in particular poor students in Ningshan) may be receiving more attention in junior high school and — even without the tuition relief policy—would have improved their test scores at a higher rate. In order to examine the robustness of our results using other approaches, in this section we employ PSM and DDM analysis to see if results from these different estimation strategies are consistent with those from the DD estimates above. 
In fact, the results of both PSM and DDM analysis are qualitatively identical and quantitatively similar with the DD results (Table 6). Rows 1 to 3 present the estimated average treatment effects on the treated (ATT) of different treatment groups. Columns 1 and 2 show the estimation results from PSM and DDM respectively. The PSM results show that the program has a positive effect on the math scores of the average students in Ningshan (compared to the average students in the control counties). The effect is 3.03 points and significant at the $1 \%$ level (Row 1). Likewise, when using Difference in Difference Matching (DDM), the average treatment effect is 2.49 and significant. As seen, the average impact on test scores when using PSM (3.03) and DDM (2.49) is close to and brackets the average impact when using DD by itself (2.85).

The results of the PSM and DDM also reveal that the greatest impact of tuition relief appears to be on the scores of the poorest students (Table 6, rows 2 and 3). When we use PSM, the average test scores of the poorest students in the treatment group improved by 4.73 points when compared to the poorest students in the control group. Moreover, this result is statistically significant (row 2, column 1). By contrast, although the point estimate of the impact of the tuition relief program on the richest students in the treatment group improves by 2.07 points relative to the richest students in the control group, the gain is statistically insignificant (row 3 , column 1). Echoing these results, the difference-in-difference matching results show that the tuition relief program has a statistically significant impact on the test scores of junior high students. Moreover, this impact is significant for the poorest students, but the program seems to have no effect on the richest students (column 2, rows 2 and 3).

In sum, all three estimation strategies show that the program improves junior high students' math scores by more than 3 points. Moreover, the poorest students are indeed 
benefitting from the program. The only discrepancy is that the difference-in-difference results suggest that the richest students gained most from the program, whereas the PSM and DDM results suggest that the richest students may not have benefitted.

\section{Effect of the Tuition Relief Program by Test Scores}

In one final empirical exercise we further narrow the impact of the tuition relief program. This last exercise tests a hypothesis that is motivated by taking into account both the institutional realities of China's competitive schooling system and observations on the behavior of parents and students within the competitive system. Specifically, in this section we want to test the hypothesis that the one of the largest impacts of the tuition relief program might be expected to appear on the students in the middle of the test score range (that is, not on the worst students or the students with the lowest test scores, and not on the best students, but rather on the students in the middle of the test score distribution).

This exercise is motivated by the fact that — even if senior high school were freeChina's high schools still require students pass a competitive entrance exam. If a student's test score is too low (indicating that the student is among the poorest performing students in the county), the student would have little hope of getting a score high enough to enter high school even if he/she worked harder (because of the tuition relief program). This would be especially true of the poor (and perhaps less true for the rich who are able to purchase points to raise the effective scores for entering high school). Alternatively, if the student is among the best in the county, even when families are poor (and certainly when they are rich), there seems to always be a way that families can find the resources to get keep their child in school. Indeed, in a number of recent studies (e.g., Wang et al., 2011), it was found that high performing children — even those that are among the poorest_-find a way to keep going to school. By this logic, poorly 
performing students have given up and the best performing students already have decided to go to high school no matter the cost. Hence, it seems from this discussion that a tuition relief program might be expected to not only have the largest effect on the poor, it might have an even larger effect on students from poor families that score in the middle of the test score distribution. In fact, when we look at Table 6, the PSM results show that the program has a positive effect on the math scores of the poorest students who scored in the middle of the test score range in Ningshan (compared to the poorest students who scored in the middle in the control counties). The effect is 7.07 points and significant at the 5\% level (Row 4). Likewise, when using Difference in Differences Matching (DDM), the average treatment effect is 6.10 and significant. In sum, both PSM and DDM results show that the tuition relief program improves the score of poorest junior high students who score in the middle of the test score distribution.

\section{Summary and Discussion}

In this paper we have exploited a natural experiment to examine the effect of a senior high tuition relief program on junior high students in poor, rural schools in Shaanxi province in China. Seeking to understand whether a tuition relief program improved the academic performance of junior high students, we compared seventh grade students in Ningshan County, where a tuition relief program was implemented, to seventh graders in nearby Shiquan and Hanyin counties. We fielded a survey and administered a standardized math examination, then analyzed these data using varied estimation strategies, including Difference-in-Differences, Difference-in-Difference-in-Differences, Propensity Score Matching, and Difference-inDifference Matching. 
The descriptive and econometric results of the program effect were robust. In general, we found that the Ningshan tuition relief program positively impacted students' academic performance. Indeed, in the descriptive results and all of the models, we discovered a statistically significant rise in the change of the math scores between the control and treatment students.

More importantly, we also found (in all of the different approaches using the multivariate analyses) that the tuition relief program had the largest (and only) significant impact on poorest students. In short, and perhaps unsurprisingly, our findings demonstrate that the test scores of poorest students rose more (and significantly so) than that of other non-poor students. Our data also show that the tuition relief program did not have a statistically positive impact on the richest students, who are seldom financially constrained when making decisions whether to go to senior high school or not. This result renders additional support to the validity of the assumption in the DD analysis.

Taken together, these results may suggest that poor students work harder when they realize their families can afford high school tuition. However, it is important to realize that other potential mechanisms exist: teachers - whose wages are linked to student matriculation in highly ranked high schools - may invest more time teaching poorer students who would have otherwise dropped out after ninth grade due to financial reasons. Whatever the mechanism, the tuition relief program clearly and positively impacts students' academic performance far before ninth grade. The final results of the paper also suggest that the impact is even more narrowly focused on students in the middle of the grade distribution. As such, if China wants to encourage studentseven poorly performing students - to stay in school, other means need to be used.

As cautioned above, our conclusions must be tempered by the limitations of this study. Even though we drew upon multiple estimation strategies that consistently pointed to the positive 
impact of the Ningshan tuition relief program, we believe that it is important to carry out further studies in order to confirm the robustness of the findings of this one natural experiment. Additionally, as a program implemented in only one county, we are limited in the generalizations we can make from the study. Even if students in Ningshan benefitted from the program, the fact is that it might be a result that is unique to this one county.

Nonetheless, to our knowledge, this is the only study that explores the impact of a tuition relief program in China. Moreover, this study shows that a tuition relief program in senior high school has impacts as early as seventh grade. To truly improve the odds of poor rural students in their senior high school participation, strategies that have impacts early in students' educational careers are particularly important. By reducing the academic performance gap early in students' career, poor students have a much better chance at senior high participation.

Finally, the results of this study contribute to a broader policy debate about how to effectively invest in rural education. Recently there has been an increasing support in the Ministry of Education (MOE) for greater investment into rural education. Opinions are divided on how money should be invested. Our results suggest that China's top educational officials should at least provisionally expand tuition relief programs in poor rural areas as an additional way to improve the human capital in rural areas. If future evaluations of tuition relief programs also show results consistent to ours, China should consider waiving senior high tuition for all poor students. 


\section{Reference}

Ankang Statistics Bureau. 2009. "Statistical Communiqué on Economic and Social Development in the Prefecture of Ankang in Shaanxi Province in 2008", http://www.shaanxi.gov.cn/0/1/65/365/371/67147.htm

Abadie, A., and G. Imbens. 2006a. "Large sample properties of matching estimators for average treatment effects." Econometrica 74: 235-267.

Abadie, A., and G. Imbens. 2006b. "On the failure of the bootstrap for matching estimators." National Bureau Of Economic Research, Technical Working Paper 325.

Brown, P., \& Park, A. 2002. "Education and poverty in rural China." Economics of Education Review 21(6): 523-541.

Cai F. 2007. "Lewis turning point is just ahead", Social Security in China, 5: 24-26

Connelly, R., \& Zheng, Z. 2003. "Determinants of school enrollment and completion of 10 to 18 year olds in China.” Economics of Education Review, 22(4): 379-388.

Cybinski P.J. and Forster J., 2009. "Student Preparedness, effort and academic performance in a quantitive business course." Discussion Papers in Economics, Griffith University, No. 2009-06,

Dehejia, R. H., and S. Wahba. 1999. "'Causal Effects in Nonexperimental Studies: Reevaluating the Evaluation of Training Programs." Journal of American Statistical Association 94: 10531062.

Dehejia, R. H., and S. Wahba. 2002. "Propensity Score-Matching Methods for Nonexperimental Causal Studies.” The Review of Economics and Statistics 84: 151-161.

Hanushek, E. A., and S. G. Rivkin. 2006. "School Quality and the Black-White Achievement Gap." National Bureau of Economic Research, Inc NBER Working Papers No. 12651.

Huang, J., H. Zhi and Z. Huang. 2011. "The Impact of the Global Financial Crisis on Off-farm Employment and Earnings in Rural China." World Development 39(5): 797-807.

Knight, J., \& Song L. 2000. "Differences in educational access in rural China”. Working paper, Department of Economics, University of Oxford.

Lei, W. 2005. Expenditure on Private Tutoring for Senior Secondary Students: Determinants and Policy Implications. Education and Economy 1:39-42. (in Chinese)

Lei, W., Zhong, Y. 2003. "An Empirical Study of the Expenditure on Education of the Rural Families in China: 1985-1999." Theory and Practice of Education 23(7): 38-42. (in Chinese) 
Luo R. Sharbono. B, Rozelle, S., 2008, "the Financial and Informational Obstacles for the Senior High Students in Rural China", REAP working papers.

Liu C., Zhang L., Luo R., Rozelle S., Sharbono B., Shi Y. 2009. "Development Challenges, Tution Barriers and High School Education in China." Asia Pacific Journal of Education, 29(4): 503-520

Ministry of Education, 2009, "160 million students in Primary and Junior High Schools have benefitted from the Free Tuition Program", http://edu.people.com.cn/GB/10039775.html

Ministry of Education, 2010, "National Educational Reform and Development Plan for MidTerm and Long-Term (2010-2020)”, http://www.gov.cn/jrzg/2010-07/29/content_1667143.htm

Mo D., Zhang L., Yi H., Luo R., Rozelle S., Brinton C., 2011. "School Dropouts and Conditional Cash Transfers: Evidence from a Randomized Controlled Trial in Rural China's Junior High Schools.” working paper, REAP, Stanford University

Natriello G., and Mcdill, E. L., 1986. "Performance Standards, Student Effort on Homework, and Academic Achievement.” Sociology of Education, Vol. 59, No. 1:pp. 18-31

Li H. W. Liu, N. Ma, J. Zhang. 2006. "Does Education Pay in Urban China? Estimating Returns to Education Using Twins.” Discussion Papers, Chinese University of Hong

Kong, Department of Economics. Loyalka P., Song Y., Wei, J., and Rozelle S., 2010. "Information, College Decision and Financial Aid: Evidence from a Cluster-randomized Control Trial in China", working paper, REAP, Stanford University

Rosenbaum, P., and D. B. Rubin. 1983. "The central role of the propensity score in observational studies for causal effects.” Biometrika 70: 41-55

Rosenbaum, P., and D. B. Rubin. 1985. "Constructing a control group using multivariate matched sampling methods that incorporate the propensity score." American Statistician 39: 3338

Rozelle, S., Zhang L., Luo R., Yi H. and Shi Y., 2012. "Avoiding the Middle Income Trap: Rural Education, Health and Building the Skills Needed in China's 21st Century Economy." Working Paper. REAP, Stanford University.

Smith, J. 2004. "Evaluating the Local Economic Development Policies: Theory and Practice." Unpublished, College Park, Maryland.

Smith, J., and P. Todd. 2005. "Does Matching Overcome Lalonde's Critique of Nonexperimental Estimators?” Journal of Econometrics 125:305-353. 
Wang X., Liu C., Zhang L., Luo R., Glauben T., Shi Y., Rozelle S., and Sharbono B. 2011. "What is keeping the poor out of college?: Enrollment rates, educational barriers and college matriculation in China." China Agricultural Economic Review, DOI:

10.1108/17561371111131281

Yang D. 2006, Equitable Education in China: dream and reality, Peking University Publishing House.

Yates J. F., Jagacinski C. M. and Taubman A. J., 1979. "Academic performance as a perceived function of ability and effort." Motivation and Emotion, Vol.3, No.2: pp.171-182

Yi H., Zhang L., Luo R., Shi Y., Rozelle S. and Chu J., 2012. "Impact of the Tuition Relief Program in Senior High School on Junior High Students' Matriculation rate to Senior High School: Evidence from a Natural Experimentl in Rural China." working paper, REAP, Stanford University

Zhang, Junsen, Yaohui Zhao, Albert Park and Xiaoqing Song, 2005. "Economic Returns to Schooling in Urban China, 1988 to 2001". Journal of Comparative Economics, 33: 730-752 
Table 1. Sample Average for the Students in the Treatment Group and Control Group in $2009^{\text {a }}$

\begin{tabular}{|c|c|c|c|c|}
\hline & & $\begin{array}{l}\text { (1) Treatment } \\
\text { group }\end{array}$ & $\begin{array}{l}\text { (2)Control } \\
\text { group }\end{array}$ & $\begin{array}{l}\text { (3) Difference in } \\
\text { mean } \\
(1)-(2)\end{array}$ \\
\hline$(1)$ & $\begin{array}{l}\text { Raw math test score in } 2009 \\
\text { (full score }=100 \text { ) }\end{array}$ & $\begin{array}{c}54.82 \\
(15.29)\end{array}$ & $\begin{array}{c}54.29 \\
(17.33)\end{array}$ & $\begin{array}{c}0.54 \\
(0.72)\end{array}$ \\
\hline$(2)$ & Age of the student (year) & $\begin{array}{l}12.92 \\
(0.81)\end{array}$ & $\begin{array}{l}13.06 \\
(1.00)\end{array}$ & $\begin{array}{c}-0.14 \\
(3.28)^{* * *}\end{array}$ \\
\hline$(3)$ & Boy Student (\%) & $\begin{array}{l}49.18 \\
(0.50)\end{array}$ & $\begin{array}{l}53.20 \\
(0.50)\end{array}$ & $\begin{array}{c}-4.02 \\
(1.81)^{*}\end{array}$ \\
\hline$(4)$ & $\begin{array}{l}\text { Student attended Kindergarten } \\
(\%)\end{array}$ & $\begin{array}{l}16.47 \\
(0.37)\end{array}$ & $\begin{array}{l}15.15 \\
(0.36)\end{array}$ & $\begin{array}{c}1.31 \\
(0.82)\end{array}$ \\
\hline$(5)$ & $\begin{array}{l}\text { Student attended the Preschool } \\
(\%)\end{array}$ & $\begin{array}{l}93.26 \\
(0.25)\end{array}$ & $\begin{array}{l}93.19 \\
(0.25)\end{array}$ & $\begin{array}{c}0.07 \\
(0.06)\end{array}$ \\
\hline (6) & Student without any sibling (\%) & $\begin{array}{l}28.27 \\
(0.45)\end{array}$ & $\begin{array}{l}25.89 \\
(0.44)\end{array}$ & $\begin{array}{c}2.38 \\
(1.21)\end{array}$ \\
\hline$(7)$ & Age of the father (year) & $\begin{array}{l}39.48 \\
(4.78)\end{array}$ & $\begin{array}{l}40.62 \\
(5.08)\end{array}$ & $\begin{array}{c}-1.14 \\
(5.02) * * *\end{array}$ \\
\hline$(8)$ & Age of the mother (year) & $\begin{array}{l}36.73 \\
(4.26)\end{array}$ & $\begin{array}{l}37.64 \\
(4.72)\end{array}$ & $\begin{array}{c}-0.91 \\
(-4.34) * * *\end{array}$ \\
\hline$(9)$ & $\begin{array}{l}\text { Father completed the middle } \\
\text { school, }(\%)\end{array}$ & $\begin{array}{l}44.13 \\
(0.50)\end{array}$ & $\begin{array}{l}38.33 \\
(0.49)\end{array}$ & $\begin{array}{c}5.79 \\
(2.65) * * *\end{array}$ \\
\hline$(10)$ & $\begin{array}{l}\text { Mother completed the middle } \\
\text { school, }(\%)\end{array}$ & $\begin{array}{l}36.87 \\
(0.48)\end{array}$ & $\begin{array}{l}24.52 \\
(0.43)\end{array}$ & $\begin{array}{c}12.35 \\
(6.16) * * *\end{array}$ \\
\hline (11) & $\begin{array}{l}\text { Father mainly worked in } \\
\text { agriculture }(\%)\end{array}$ & $\begin{array}{l}33.04 \\
(0.47)\end{array}$ & $\begin{array}{l}30.10 \\
(0.46)\end{array}$ & $\begin{array}{c}2.94 \\
(1.43)\end{array}$ \\
\hline (12) & $\begin{array}{l}\text { Mother mainly worked in } \\
\text { agriculture }(\%)\end{array}$ & $\begin{array}{l}51.34 \\
(0.50)\end{array}$ & $\begin{array}{l}49.86 \\
(0.50)\end{array}$ & $\begin{array}{c}1.48 \\
(0.67)\end{array}$ \\
\hline (13) & $\begin{array}{l}\text { Number of family members } \\
\text { (person) }\end{array}$ & $\begin{array}{c}4.25 \\
(1.07)\end{array}$ & $\begin{array}{c}4.47 \\
(1.15)\end{array}$ & $\begin{array}{c}-0.23 \\
(4.42) * * *\end{array}$ \\
\hline
\end{tabular}

Data: Authors' survey.

Note:

a. Standard deviations are reported in parentheses for columns (1) and (2); absolute values of t-statistics are reported in column (3);

* significant at $10 \%$; * significant at 5\%; *** significant at $1 \%$. 
Table 2. Change in Student Math Score between 2009 and $2010{ }^{\mathrm{a}}$

\begin{tabular}{|c|c|c|c|c|c|}
\hline \multicolumn{6}{|c|}{ Panel A Change in Raw Math Score } \\
\hline & & Full Sample & $\begin{array}{l}\text { Treatment } \\
\text { group }\end{array}$ & Control group & $\begin{array}{c}\text { Difference } \\
\text { (t-statistics in } \\
\text { parenthesis) }\end{array}$ \\
\hline & & $(1)$ & $(2)$ & (3) & $(4)=(2)-(3)$ \\
\hline (1) & Mean Score in 2009 & $\begin{array}{c}54.42 \\
(16.85)\end{array}$ & $\begin{array}{c}54.82 \\
(15.29)\end{array}$ & $\begin{array}{c}54.29 \\
(17.33)\end{array}$ & $0.53 \quad(0.72)$ \\
\hline (2) & Mean Score in 2010 & $\begin{array}{c}70.44 \\
(16.61)\end{array}$ & $\begin{array}{c}73.19 \\
(15.49)\end{array}$ & $\begin{array}{c}69.55 \\
(16.87)\end{array}$ & $3.64(4.96) * * *$ \\
\hline (3) & $\begin{array}{l}\text { Difference }=(2)-(1) \\
(\mathrm{t}-\text { statistics in } \\
\text { parenthesis })\end{array}$ & $\begin{array}{c}16.02 \\
(35.45) * * *\end{array}$ & $\begin{array}{c}18.37 \\
(21.88)^{* * * *}\end{array}$ & $\begin{array}{c}15.26 \\
(28.71)^{* * *}\end{array}$ & $3.11(2.96)^{* * *}$ \\
\hline \multicolumn{6}{|c|}{ Panel B Change in Normalized Math Score ${ }^{b}$} \\
\hline (4) & Mean Score in 2009 & & 0.02 & -0.01 & $0.03 \quad(0.72)$ \\
\hline$(5)$ & Mean Score in 2010 & & 0.17 & -0.05 & $0.22(4.96) * * *$ \\
\hline (6) & $\begin{array}{l}\text { Difference }=(2)-(1) \\
(\mathrm{t} \text {-statistics in } \\
\text { parenthesis })\end{array}$ & & $\begin{array}{c}0.15 \\
(2.82) * * *\end{array}$ & $\begin{array}{l}-0.04 \\
(1.45)\end{array}$ & $0.19(2.99)^{* * *}$ \\
\hline
\end{tabular}

Data: Authors' survey.

Note:

a. Standard deviations are reported in parentheses in row (1) and (2); and absolute values of t-statistics are reported in parentheses in row (3) and column (4). * significant at 10\%; ** significant at 5\%; *** significant at $1 \%$.

b. The normalized scores were created by subtracting the average test score in one year of all sample students from the test for each student and then dividing each score by the standard deviation of the test scores of all sample students in the same grade. 


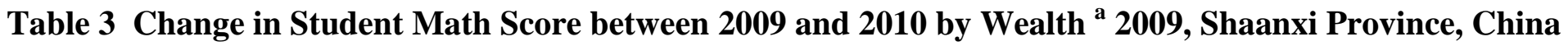

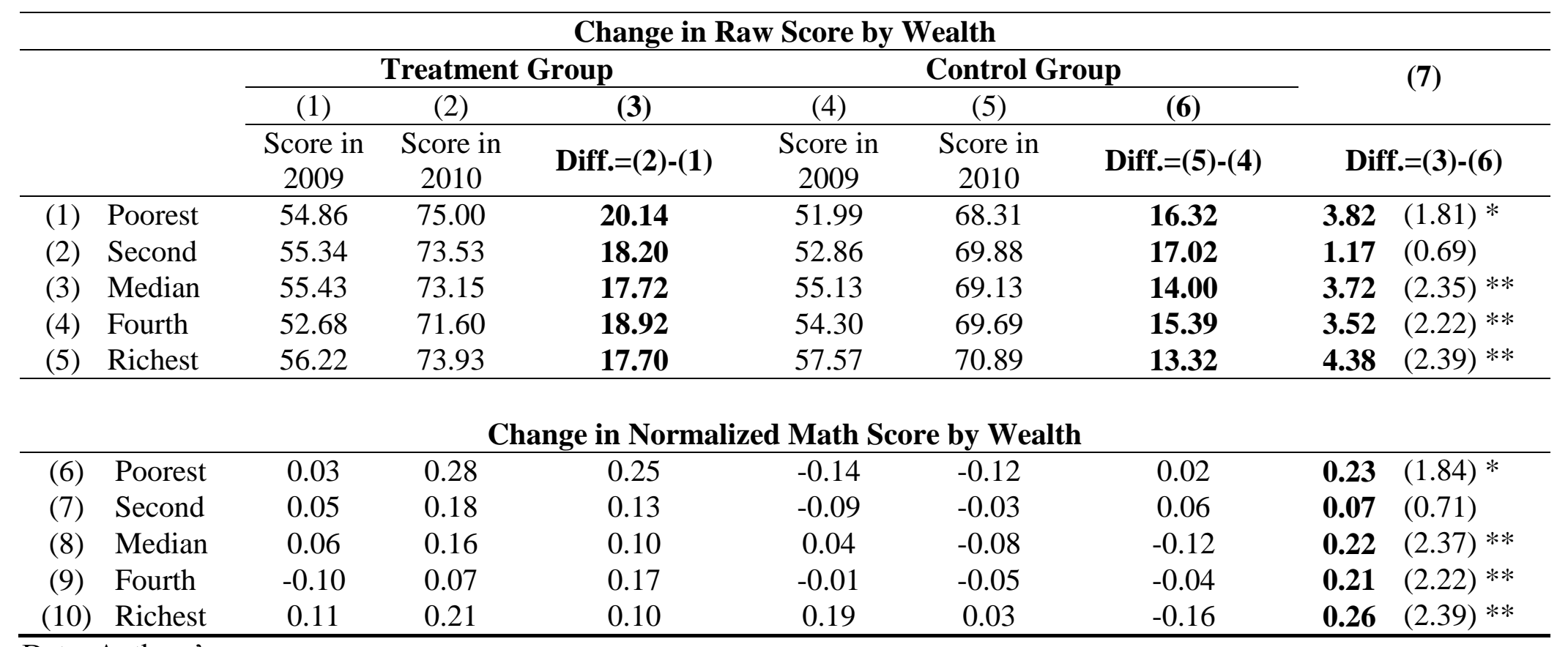

Data: Authors' survey.

Note:

a. Asset Index is created to measure the wealth using principle component analysis. To be specific, following the method by Filmer and Pritchett (1998), we use the scoring factors from the first principal component to create the asset index. It is in fact a weighted average of the observed 30 variables of assets and variables with higher coefficients have more weight in determining the score on this component. The higher the asset index is, the wealthier the household is. In Panel A and B, the sample students are divided into five groups based on the asset index, ranging from the poorest to the richest.

b. Absolute values of t-statistics are reported in parentheses in column (7). * significant at 10\%; ** significant at 5\%; *** significant at $1 \%$. 
Table 4 Difference-in-Difference Regressions Evaluating the Effects of Tuition Relief Program on the Math Score of the Students, Shaanxi Province, China a

Dependent Variable $\left(4\right.$ Score $\left._{i}\right)=$ Score $_{i, 2010}-$ Score $_{i, 2009}$

\begin{tabular}{|c|c|c|c|c|c|}
\hline & & (1) & (2) & (3) & (4) \\
\hline (1) & $\begin{array}{l}\text { Program dummy } \\
\text { (1=participated in the } \\
\text { program) }\end{array}$ & $\begin{array}{c}3.11 \\
(4.04)^{*} \\
* *\end{array}$ & $\begin{array}{c}3.29 \\
(2.29)^{* *}\end{array}$ & $\begin{array}{c}3.40 \\
(5.22)^{* * *}\end{array}$ & $\begin{array}{c}2.85 \\
(1.82)^{*}\end{array}$ \\
\hline (2) & $\begin{array}{l}\text { Math score in } 2009 \text { (full } \\
\text { score }=100 \text { ) }\end{array}$ & & & $\begin{array}{c}-0.55 \\
(32.83)^{* *} \\
*\end{array}$ & $\begin{array}{c}-0.58 \\
(29.60)^{* *} \\
*\end{array}$ \\
\hline (3) & Age of the student (year) & & $\begin{array}{c}-0.72 \\
(1.77)^{*}\end{array}$ & & $\begin{array}{c}-2.11 \\
(6.01)^{* * *}\end{array}$ \\
\hline (4) & Gender dummy(1=boy, $)$ & & $\begin{array}{c}1.19 \\
(1.48)\end{array}$ & & $\begin{array}{c}2.68 \\
(2.91)^{* * *}\end{array}$ \\
\hline (5) & $\begin{array}{l}\text { Kindergarten dummy } \\
\text { (1=attended the } \\
\text { kindergarten, })\end{array}$ & & $\begin{array}{l}1.36 \\
(1.20)\end{array}$ & & $\begin{array}{c}1.84 \\
(1.85)^{*}\end{array}$ \\
\hline (6) & $\begin{array}{l}\text { Preschool dummy }(1= \\
\text { attended preschool) }\end{array}$ & & $\begin{array}{c}1.94 \\
(1.12)\end{array}$ & & $\begin{array}{c}2.91 \\
(1.94)^{*}\end{array}$ \\
\hline (7) & $\begin{array}{l}\text { No Sibling dummy } \\
\text { (1= no siblings,) }\end{array}$ & & $\begin{array}{c}-2.26 \\
(2.20)^{* *}\end{array}$ & & $\begin{array}{l}-1.27 \\
(1.29)\end{array}$ \\
\hline (8) & Age of the father (year) & & $\begin{array}{c}0.11 \\
(0.99)\end{array}$ & & $\begin{array}{c}0.11 \\
(1.27)\end{array}$ \\
\hline (9) & Age of the mother (year) & & $\begin{array}{l}-0.01 \\
(0.08)\end{array}$ & & $\begin{array}{l}-0.07 \\
(0.77)\end{array}$ \\
\hline (10) & $\begin{array}{l}\text { Education dummy for father } \\
\text { (1= father completed middle } \\
\text { school) }\end{array}$ & & $\begin{array}{l}-0.52 \\
(0.84)\end{array}$ & & $\begin{array}{l}0.76 \\
(1.20)\end{array}$ \\
\hline (11) & $\begin{array}{l}\text { Education dummy for } \\
\text { mother }(1=\text { mother } \\
\text { completed middle school) }\end{array}$ & & $\begin{array}{l}-0.27 \\
(0.35)\end{array}$ & & $\begin{array}{c}1.00 \\
(1.23)\end{array}$ \\
\hline (12) & $\begin{array}{l}\text { Occupation dummy for } \\
\text { father }(1=\text { work in agriculture })\end{array}$ & & $\begin{array}{l}-0.33 \\
(0.34)\end{array}$ & & $\begin{array}{l}-0.75 \\
(0.88)\end{array}$ \\
\hline (13) & $\begin{array}{l}\text { Occupation dummy for } \\
\text { mother( } 1=\text { work in } \\
\text { agriculture })\end{array}$ & & $\begin{array}{c}1.22 \\
(1.19)\end{array}$ & & $\begin{array}{c}0.42 \\
(0.59)\end{array}$ \\
\hline (14) & $\begin{array}{l}\text { Number of family members } \\
\text { (person) }\end{array}$ & & $\begin{array}{c}0.70 \\
(1.50)\end{array}$ & & $\begin{array}{c}0.06 \\
(0.17)\end{array}$ \\
\hline (15) & $\begin{array}{l}\text { Second poorest dummy }{ }^{\mathrm{b}} \\
\text { (bottom } 20 \% \text { - bottom } 40 \% \text { ) }\end{array}$ & & $\begin{array}{c}0.22 \\
(0.16)\end{array}$ & & $\begin{array}{c}0.56 \\
(0.46)\end{array}$ \\
\hline (16) & $\begin{array}{l}\text { Median dummy }{ }^{\text {b }} \\
\text { (bottom } 40 \% \text { - bottom } 60 \% \text { ) }\end{array}$ & & $\begin{array}{c}-1.62 \\
(1.68)\end{array}$ & & $\begin{array}{l}-0.19 \\
(0.22)\end{array}$ \\
\hline (17) & $\begin{array}{l}\text { Second richest dummy }{ }^{\mathrm{b}} \\
\text { (Top 20\%- Top 40\%) }\end{array}$ & & $\begin{array}{l}-0.34 \\
(0.30)\end{array}$ & & $\begin{array}{c}0.11 \\
(0.10)\end{array}$ \\
\hline (18) & $\begin{array}{l}\text { Richest dummy }{ }^{\mathrm{b}} \\
\text { (>Top 20\% quintile) }\end{array}$ & & $\begin{array}{l}-2.06 \\
(1.22)\end{array}$ & & $\begin{array}{c}0.05 \\
(0.04)\end{array}$ \\
\hline
\end{tabular}




\begin{tabular}{llcccc}
\hline$(19)$ & Observations & 2742 & 2264 & 2742 & 2264 \\
$(20)$ & R-squared & 0.01 & 0.02 & 0.29 & 0.32 \\
\hline
\end{tabular}

Data source: Authors' survey.

Note:

a. the dependent variable is the change in raw math test score.

Absolute values of t-statistics are in parentheses. * significant at $10 \%$; ** significant at $5 \%$; *** significant at $1 \%$

b. The dummies indicating the wealth are the same as table 3 and the comparison group is the poorest (bottom 0-20\%) students. 
Table 5 Regressions Evaluating the Effects of Tuition Relief Program on the Effort of the Poorest Students, Shaanxi Province, China ${ }^{\text {a }}$

Results of raw score using program dummy interacted with poorest dummy

Dependent Variable $\left(\Delta\right.$ Score $\left._{i}\right)=$ Score $_{i, 2010}-$ Score $_{i, 2009}$

(1) Program dummy (1=participated in the program)

(2) Poorest dummy ${ }^{\mathbf{b}}$ (1=Poorest)

$-0.75$

(3) Interaction term of Poorest and Program dummy

(Program*Poorest)

3.83

(4) Math score in 2009 (full score $=100$ )

$(2.99) * * *$

$-0.59$

(5) Age of the student (year)

$-2.13$

$(6.25)^{* * * *}$

2.70

(6) Gender dummy (1=boy,)

$(2.95)^{* * *}$

(7) Kindergarten dummy

1.88

(1=attended the kindergarten,)

$(1.87)^{*}$

3.01

(8) Preschool dummy (1= attended preschool)

$(2.02)^{*}$

(9) No Sibling dummy

$-1.30$

(1= no siblings,

$(1.35)$

(10) Age of the father (year)

0.11

$(1.31)$

(11) Age of the mother (year)

$-0.08$

$(0.86)$

Education dummy for father $(1=$ father completed

0.77

middle school)

(1.23)

Education dummy for mother $(1=$ mother $\quad 1.02$

completed middle school)

Occupation dummy for father(1=work in

$-0.77$

agriculture)

$(0.89)$

Occupation dummy for mother( $1=$ work in

0.43

agriculture)

$(0.61)$

0.05

(16) Number of family members (person)

(0.14)

(17) Observations

2264

(18) R-squared

0.32

Data source: Authors' survey.

Note:

a. Absolute values of t-statistics are in parentheses. The estimates are adjusted for inflation.

* significant at $10 \%$; ** significant at $5 \%$; *** significant at $1 \%$

b. The poorest dummy is the same as table 3. It equals 1 if the asset index of the household is among the bottom $1 / 5$.

c. The controls are the same as those in table 4. 
Table 6. Evaluating the Effects of Tuition Relief Program on the Efforts of Students in using Propensity Score Matching and Difference-in-Difference Matching, Shaanxi Province, China ${ }^{\mathrm{a}}$.

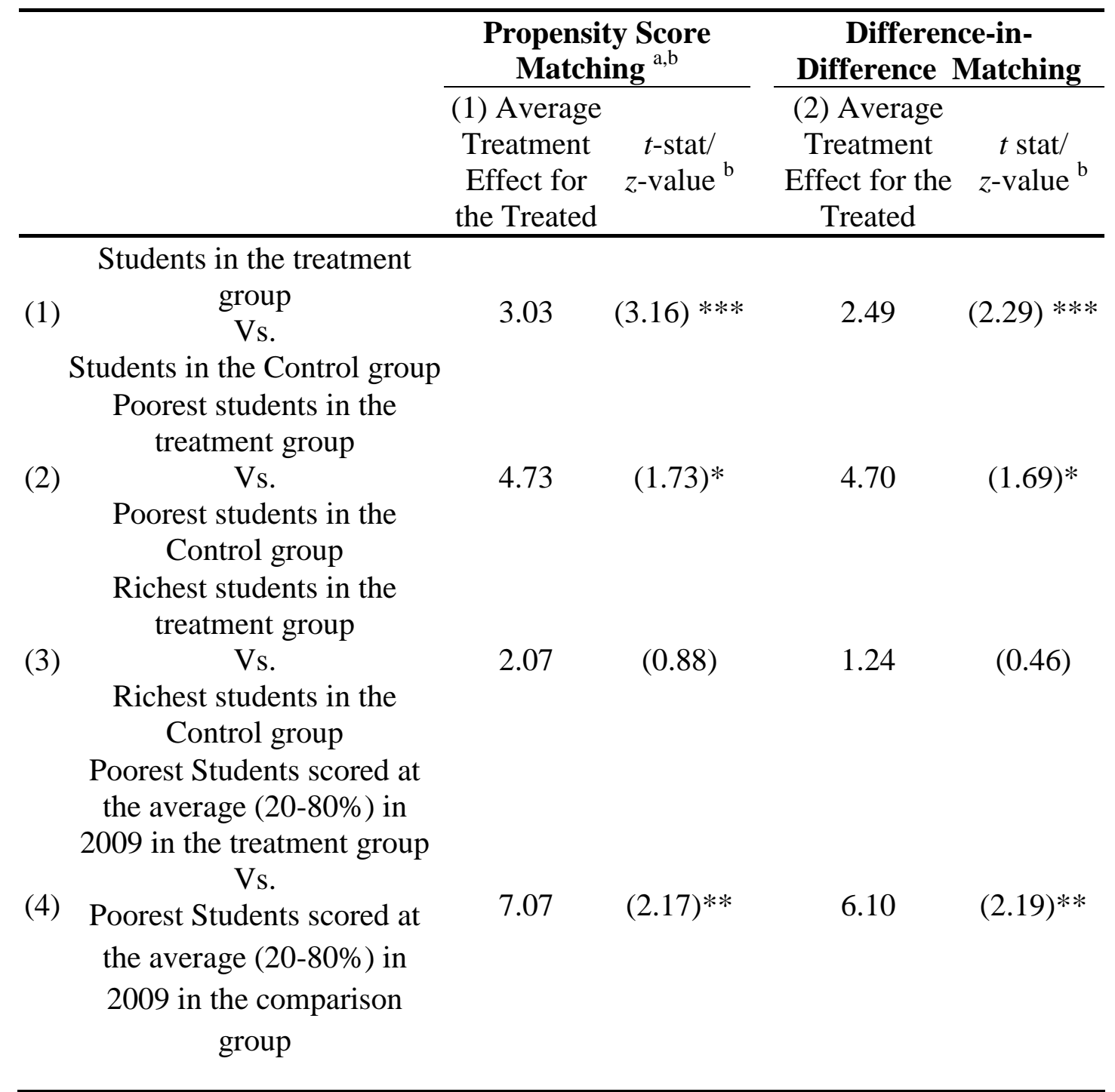

Data: Authors' survey.

${ }^{\text {a }}$ Propensity scores are estimated using the same set of covariates as in Table 4.

And poorest students are the students whose asset value is the lowest (0-20\%) among all students.

${ }^{b}$ The balancing property was satisfied using the specification. Following Smith and Todd (2004) we match on the log odds-ratio so that the estimates are robust to choice-based sampling. The matching method used is nearest neighbor matching method (random draw version) with replacement

c. $\mathrm{t}$ statistics are reported for propensity score matching. The standard errors were bootstrapped using 1000 replications. * denotes significant at $10 \%$ level, ** denotes significant at 5\% level, * **denotes significant at $1 \%$ level. 
Baseline (Sept. 2009)

All 6 junior high schools in the County of Ningshan (treatment Group) and all 30 junior high schools were selected in the County of Shiquan and

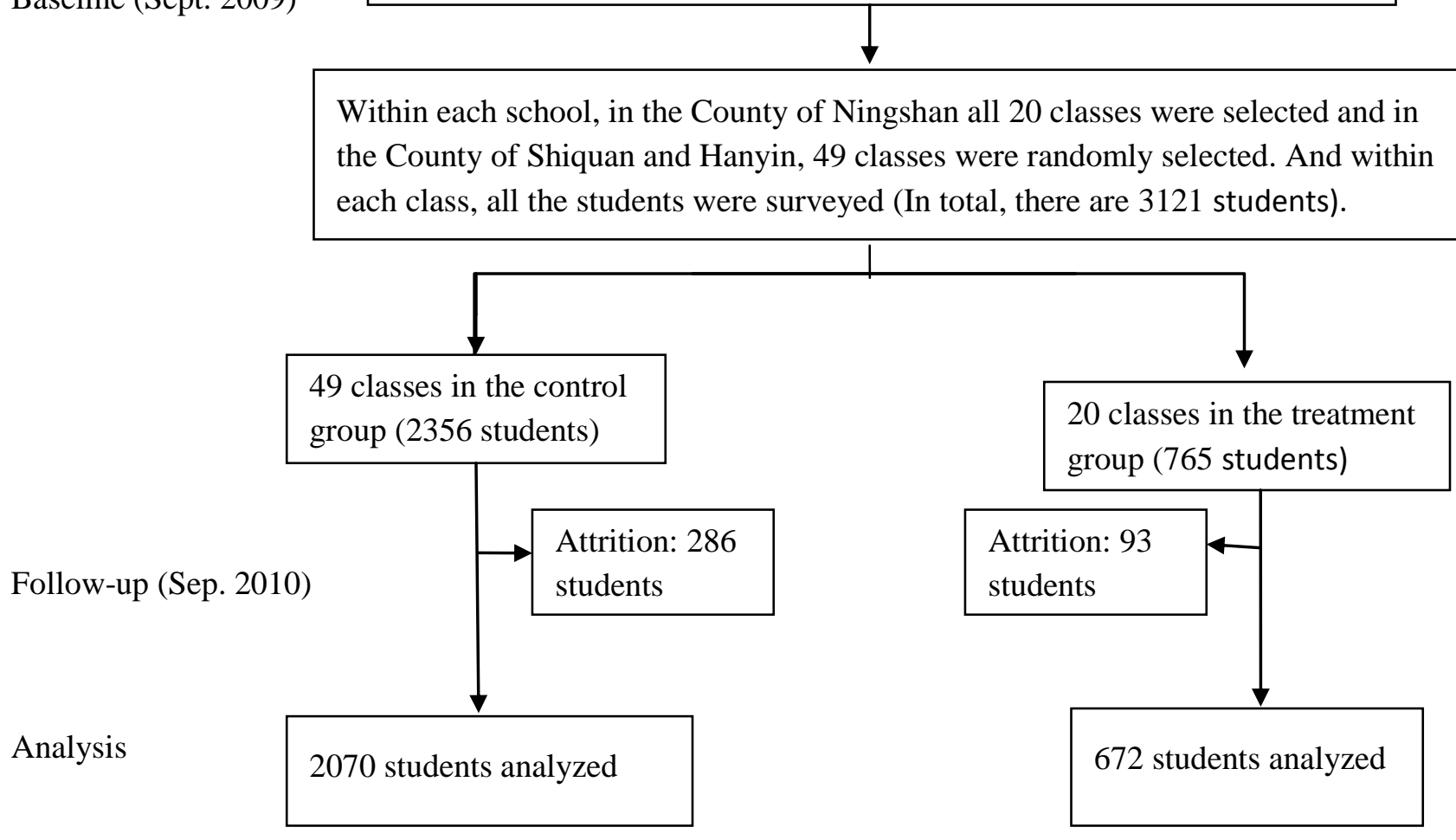

Figure 1: Experiment Profile 